\title{
Re-discovering the Quechua adjective
}

SIMEON FLOYD

\begin{abstract}
This article describes the adjective class in Quechua, countering many previous accounts of the language as a linguistic type with no adjective/noun distinction. It applies a set of common crosslinguistic criteria for distinguishing adjectives to data from several dialects of Ecuadorian Highland Quechua (EHQ), analyzing examples from a natural speech audio/video corpus, speaker intuitions of grammaticality, and controlled elicitation exercises. It is concluded that by virtually any standard Quechua shows clear evidence for a distinct class of attributive noun modifiers, and that in the future Quechua should not be considered a "flexible" noun/adjective language for the purposes of crosslinguistic comparison.
\end{abstract}

Keywords: adjectives, anaphora, attribution, compounds, ellipsis, inflection, nouns, Quechua, syntax, word classes

\section{Introduction}

\subsection{Quechua word classes and word class typology}

In discussions of parts of speech typology linguists have often cited Quechua as an exemplary case of a language type with just two major word classes, the first including verbs and the second including both nouns and adjectives with no formal distinction between them (Hengeveld 2007, forthcoming; Hengeveld \& van Lier 2008; Smit 2007; Gómez Rendón 2008; Hengeveld \& Valstar 2010; etc.). To some extent, the diffusion of this analysis of Quechua can be traced to Schachter's influential treatment of parts of speech $(1985,2$ nd edn. as Schachter \& Shopen 2007), frequently cited in literature on word class typology. My intention in this article is to show that there is strong counterevidence to this characterization, with the hope that Quechua be included in future typological studies in a way that better reflects the facts. 
Countering this entrenched account of Quechua also means confronting a problem in parts of speech typology more generally because there is little consensus among linguists as to what count as valid crosslinguistic criteria for word classes. Schachter's criteria for positing a single noun/adjective class for Quechua rest on three morphosyntactic observations: (i) adjectives can receive some of the same morphology as nouns, (ii) both nouns and adjectives can modify nouns, and (iii) adjectives can sometimes head noun phrases with no accompanying noun. All of these statements have some degree of literal accuracy, but at the same time they fail to account observations in natural speech where a whole range of regular constraints restrict the possibilities of nouns and adjectives for occurring EQUALLY in any of these morphosyntactic contexts. Rather than relying on just one or a few specific features, the basic criteria for establishing a lack of word class distinction that I will respect here is that the morphosyntactic possibilities should be the same for all members of the proposed macro-class exhaustively across the lexicon (following Evans \& Osada 2005). In order to establish the lack of interchangeability between Quechua nouns and adjectives, I will further enumerate and apply a number of the most common specific criteria that have been used for distinguishing adjectives from nouns in the world's languages (following Dixon 2010: 106-107). These criteria are judged to be relevant here insofar as they reflect word class distinctions in typologically diverse crosslinguistic contexts and form part of the cumulative body of knowledge that can be referred to as "basic linguistic theory" (Dixon 2010, Dryer 2006).

I will apply these criteria to many examples from a diverse data sample to arrive at an analysis of word classes that can account for a natural speech corpus including multiple varieties and discourse forms of Ecuadorian Quechua. ${ }^{1}$ For fellow Quechuanists, I propose that despite some views to the contrary, for many varieties of Quechua we can find overwhelming justification for distinguishing word classes that in a crosslinguistic sense are most reasonably called "adjective" and "noun". For those using Quechua for typological comparison, on the other hand, I hope that my account of Quechua will allow the language to be included in comparisons of parts of speech systems in a more meaningful way.

1. Except for some negative examples generated for comparison through elicitation, the examples in this article are largely taken from an audio/video transcribed text collection of approximately ten hours of natural speech in the Imbabura, Cotopaxi, Pichincha, and Cañari dialects of Ecuadorian Highland Quichua collected by the author between 2001 and 2008. In addition, some complementary data from elicitation exercises will also be considered. While this corpus is not particularly large, it represents a diverse sample of language varieties and discourse forms, including informal conversation and several types of monologic texts such as narratives and traditional stories. 


\subsection{Criteria for parts of speech systems and adjectives crosslinguistically}

The crosslinguistic universality of the adjective category has been argued from both formalist (Baker 2003) and typological (Dixon 2004, 2010) perspectives. I do not take a strong position here regarding the adjective's universality; I myself went on for some time accepting the idea that Quechua has no distinct adjective class until direct experience with the language obliged me to change my viewpoint. However, it is clear that the different proposed criteria for distinguishing word classes crosslinguistically (such as in Dixon 2004: 14-15, Evans \& Osada 2005: 366-384, Munro 2005: 311) are based on very real similarities among parts of speech systems in diverse unrelated languages, and that some assumptions about crosslinguistic comparability can be profitable descriptive tools. However, the question of WHICH of the possible criteria to value over others when distinguishing word classes is much less clear. An argument about word classes in an agglutinative language might rest on morphological evidence that would be irrelevant for understanding word classes in an isolating language, for example.

Starting with the list of criteria in Dixon 2010, which is the most exhaustive list of criteria that I know of for distinguishing adjectives in languages where they share some features with nouns, it is possible to initially eliminate some criteria that simply do not apply to a language of Quechua's typological profile. For example, because Quechua does not have obligatory grammatical number or gender agreement for nouns and modifiers, it is impossible to use these feature as criteria for identifying adjectives. ${ }^{2}$ Eliminating these, I will apply the remaining criteria to Quechua (listed below) in the course of this article, in the following order (re-ordered and edited/reduced, from Dixon 2010: 106-107):

(i) If a noun can be modifier to a noun phrase head, are its modifier properties equal to those of adjectives? (This question will be addressed in Section 2.)

(ii) Is there morphology that applies to both nouns and adjectives but with different meanings? (Section 3.)

(iii) Does reduplication apply to adjectives and not to nouns? (Section 4.)

(iv) Can an adjective make up a noun phrase all by itself? Is this best described as an elliptical noun phrase, with head omitted, or as a noun phrase for which the adjective is head? If an adjective is noun phrase head, can it be modified in the same way as a noun as head? Can both adjective and

2. I will not apply several of Dixon's criteria here because of issues of space and because these would not clearly distinguish nouns and adjectives in Quechua. This shows that Quechua adjectives do have some limited similarities with nouns - they can both be verbalized in the same way, for example - but then verb roots can be causativized in the same way as nouns and adjectives, so this is not a clear test. Both word classes can also both function as a copula complement, but this function is shared by adjectives and nouns in many languages. 
noun modifiers be used anaphorically for a full noun phrase? (Sections 5 and 6.)

These criteria are based on known recurring crosslinguistic patterns. Different linguists might favor some of them over others, but the fact that so many different features tend to align along the noun/adjective border, in my view, outweighs the relative importance of each individual criterion alone. There will always be "mis-matched" languages as well, in which these different dimensions do not neatly align (Olawsky 2004, Nikolaeva 2008). These difficulties are part of why the topic of parts of speech systems continues to attract attention and debate (see the recent articles in Ansaldo et al. (eds.) 2008; Smith 2010 and replies in Baker 2010 and Croft 2010). For example, Evans \& Osada (2005) critiqued the classification of Mundari as a language that is "flexible" with respect to nouns and verbs, followed by replies defending the language's "flexibility" (Peterson 2005, Hengeveld \& Rijkhoff 2005). Linguists are constantly revising earlier accounts, and languages that, like Quechua, have been described as having "no adjectives" have later been shown to have good evidence for an adjective class, as in the case of Thai (Post 2008). Statements about universals are later confronted with apparent candidates for counterexamples, as in the case of some Native American languages that challenge claims for the universality of adjectives (Chafe 2004, Palancar 2006).

Disagreements about the observable facts of these languages are only a small part of these debates, which ultimately center on difference of opinion about the type of criteria that should be applied to word classes. Some have gone as far as suggesting that crosslinguistic categories are impossible to define under any criteria (Haspelmath 2007). While this may be true in some absolute sense, the criteria applied here were chosen as practical tools on the basis of their crosslinguistic utility and for their effectiveness for making class distinctions at the specific level of major root classes (noun, verb, adjective, adverb) rather than at more general levels, such as word vs. non-word or function word vs. content word. But without consensus as to which kinds of evidence are the most relevant for determining word classes, setting the record straight for Quechua is not totally straighforward. In a recent exchange, Smith (2010) and Baker (2010) argued explicitly against using pragmatic evidence for distinguishing word classes, taking the strong position that only syntactic evidence is acceptable, while Croft (2010) countered by claiming that syntactic, semantic, and pragmatics should be jointly considered. Enfield (2006a) also points out some of the problems with considering only syntax at the expense of semantics. While personally I tend toward the broader approaches of Croft and Enfield, I think that if enough varied criteria are applied, anyone interested in including Quechua in crosslinguistic comparison should be convinced by at least several of them, even if they regard only morphosyntactic evidence as valid. In this way I hope to avoid simply adding to an endless exercise in 
"lumping" and "splitting" word classes depending on variations in the criteria applied to them (see Croft 2001, 2005) by providing enough descriptive data that linguists of any theoretical orientation might find my account useful for crosslinguistic comparison.

\subsection{The "Quechua language" and historical accounts of its parts of speech}

While Quechua is often treated as a single language, it is actually a large language family consisting of many different varieties spoken throughout the Andes from Colombia in the north to Argentina in the south. My data are limited to several dialects of Ecuadorian Highland Quechua (EHQ, known widely as "Quichua"), but since many varieties are mutually intelligible and share common features, it is probable that other Quechuas resemble EHQ with respect to word classes as I describe them here. I hope that similar questions will be addressed in the future by Quechuanists working with other varieties. I performed some limited tests with a speaker of a central Peruvian Quechua variety producing data that patterned closely with EHQ even though the two varieties are among the most divergent in the family, hinting that my analysis of EHQ may also apply to some degree across the family.

The Quechua family, including the Ecuadorian varieties, can be typologically characterized as highly agglutinative and suffixing verb-final (primarily SOV), with case marking on noun phrases and person, tense, aspect, and many other values marked on verbs. Additionally, a number of values like focus and evidentiality can be marked on almost any constituent. The language has three vowels $(a, i, u)$, a medium-sized consonant inventory, regular penultimate stress, and some regular phonological processes like voicing of unvoiced stops in specific contexts. ${ }^{3}$ A typical finite clause consists of a verb marked for person and tense along with optional overt arguments; subordinate clauses are similar, but consist of a verb with non-finite morphology, usually switch reference marking. Modifier scope is rightwards while suffix and clitic scope is leftwards.

Ecuadorian Quechua is a regional variety that differs in a number of ways from varieties spoken in other Andean countries, and that locally breaks down into a number of mutually intelligible highland Andean sub-dialects as well as several lowland Amazonian dialects that are difficult for highlanders to understand. The Quechuan languages are among the most widely spoken indigenous languages in the Americas, and have one of the longest histories of study in

3. In this article I use a practical orthography based on Spanish, so some letters do not correspond

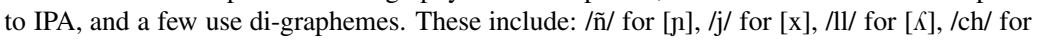
$[\mathrm{t}], / \mathrm{sh} /$ for $[\mathrm{f}]$, and /ts/ for [ts]. 
a European grammatical framework. However, there are still some persistent problems for describing Quechuan languages that have not been resolved even after all those centuries.

The earliest European accounts of Quechua generally applied the label "adjective" to words that translate to semantically attributive words in European languages, regardless of their morphosyntactic features. For example, in this excerpt from the first Quechua grammar (1560), Santo Tomás gives an ambiguous account of a nombre ("name") class with substantivo ("substantive/noun") and adjectivo ("adjective") subclasses whose semantics correspond with Spanish nouns and adjectives.

Acerca de la primera parte de la oración (que es nombre) es de notar que en esta lengua general de los indios, como en las demás lenguas, el nombre tiene su diversa manera de significar, de tal manera que unos son substantivos y otros adjectivos, v.g.: álli, que quiere decir 'cosa buena', es adjectivo; y cári, que quiere decir 'varón', es substantivo. Assí mismo tiene sus propriedades que le convienen. (Santo Tomás) 1560 [1995: 20])

[With respect to the first part of speech (which is noun [nombre]) it must be noted that in this general language of the Indians, as in all other languages, the noun has its own diverse form of meaning, such that some are nouns proper [substantivos] while others are adjectives; for example, álli, which means 'good thing', is an adjective; and cári, which means 'man' [varón], is a noun. And as such they feature the properties that correspond to them.]

While not using modern terminology, early Quechua grammarians were often near-native speakers with insights into the language, like Santo Tomás' observations here that hint at arguments I will advance below regarding the pragmatic conditions under which an adjective like 'good' can occur as the syntactic head of a noun phrase: 'good (thing)'. A related observation in a nineteenthcentury source by Ecuadorian philologist (and national president 1892 to 1895) Luis Cordero, who grew up speaking Quechua, anticipates one of the main conclusions of this article by pointing out how adjective-headed noun phrases are restricted by pragmatic conditions allowing for the "omission" of the noun.

... en la construcción quichua va siempre el adjetivo antes del nombre, según lo que ya hemos indicado, a menos que, por omisión de éste, haya quedado solo, refiriéndose a una cláusula o a un inciso anterior. Nunca se dirá, pues, allpa sinchi, chagra sumag, tamia pishi, traduciendo 'tierra dura, sementera buena, lluvia escasa', sino sinchi allpa, sumag chagra, pishi tamia. (Cordero 1892 [1992: xxviii]) [... in Quichua constructions the adjective always goes before the noun (nombre), as we have indicated, unless, by [the noun's] omission, it has been left alone, referring to a previous clause or passage. One will never say allpa sinchi, chagra sumag, tamia pishi, translating it as 'hard earth', 'good field', 'scarce rain', but instead sinchi allpa, sumag chagra, pishi tamia.] 
Cordero makes an important observation about Quechua's strict modifier-head order (Adjective Noun, AN) in the noun phrase, identifying a key syntactic difference between Quechua nouns and adjectives, which are not interchangeable with respect to their order in the noun phrase $(* \mathrm{NA})$.

Despite these early insights, Quechua grammars have in general tended to privilege semantics, calling "adjectives" anything that would commonly translate as a property concept in a European language (see Paris 1961 and Catta 1994 for EHQ). More recent accounts, on the other hand, have tended in the opposite direction, lumping nouns and adjectives together into a single "substantive" category (some of which are "typically used to modify"; Weber 1989: 36), based on "stressing the syntactic similarities between adjectives and nouns, and putting aside the semantic differences" (Muysken \& Lefebvre 1988: 27). This approach to Quechua looks first to morphosyntax to establish a form class, and only then looks to semantics to see what meanings the words of that form class tend to have. The data from EHQ shows that even an exclusively morphosyntactic approach reveals some basic distinctions between Quechua adjectives and nouns, without relying on semantics. This has been known for at least several decades for EHQ, since the publication of Cole's grammar of Imbabura Quechua (1982), one of the best sources on the language and one of the most cited in typological studies. Cole pointed out that while there are a number of similarities between nouns and adjectives, they differ with respect to their possibilities of usage with degree words, showing this example with the adjective sumak 'pretty; excellent':

$$
\begin{array}{lll}
M a y-m i & \text { sumak-mi } \quad k a-n k i \\
\text { very-EV.AFF } & \text { pretty-EV.AFF } & \text { be-2sG } \\
\text { 'You are very pretty.' (Cole } & 1982: 162 ; \text { modified orthography) }
\end{array}
$$

Examples from my corpus also show the degree word may 'very' with adjectives. Speakers do not accept its usage with nouns. ${ }^{4}$

(2) a. May alli chay puncha gente-kuna sinchi-kuna ka-rka. very good DM.DST day person-PL strong-PL be-PST 'Very good, in those days people were strong.'

b. $\tilde{N} a$ may alli riku-ri-rka nin sumak. already very good look-REFL-PST say-3sG excellent 'Now (it) looks very good, they say, excellent.'

c. *May allku rikurirka. very dog look-REFL-PST *'(It) looks very $\operatorname{dog}(\mathrm{gy})$.'

4. In addition, there are several degree or quantity words that can be used with both adjectives and adverbs, such as achka or '(very) much/many'. 
These facts noted in Cole 1982 have apparently not been enough to gain general recognition of a word class distinction between nouns and adjectives in Imbabura Quechua on their own. Here I will bring several more lines of evidence into the discussion in an effort to finally settle the issue. That evidence will consider morphosyntactic distribution as convincing on that level alone, but it will also consider some semantic and pragmatic dimensions that help to strengthen the argument. While some linguists stress the priority of morphosyntactic evidence, others consider that semantics can be jointly relevant (Munro 2005: 311, Beck 2002), as can evidence from other areas like phonology. ${ }^{5}$ Here I will take some semantic features into account, as well as evidence from discourse pragmatics concerning contexts for ellipsis; I hope to accommodate both more restricted morphosyntactic perspectives as well as more holistic multi-level perspectives on what counts as relevant evidence for word classes.

\subsection{Accounts of Quechua adjectives and nouns as a single class}

In his original chapter, the main claim made by Schachter (1985: 17) about Quechua word classes is that the language features a single noun-adjective class whose members can all equally head a noun phrase, occur as a dependent modifier of a head within a noun phrase, and occur as a copular predicate. Based on these features, Quechua falls into the "noun-like" adjective category in Dixon's (2004: 14-28) terms. Schachter's case partly rests on the observation that Quechua adjectives can apparently take "nominal" morphology such as affixes marking plural (-kuna) $)^{6}$ and accusative case (-ta). He offers the example below, comparing the adjective hatun/jatun ${ }^{7}$ 'big' to the noun alkalde 'mayor', showing how Quechua can variably use an adjective as a modifier meaning 'big' or as a noun meaning 'big one', in contrast with languages like English that (sometimes) use a dummy head noun like one.

\footnotetext{
5. Berg 2000 discusses the importance of phonology in the English parts of speech system. Ecuadorian Quechua also distinguishes word classes based on phonology, as seen in its small interjection class. In contrast to Quechua's usually strict stress assignment to the penultimate syllable, all members of the interjection class share distinctive phonological features including final syllable stress: achacháy 'How cold!', araráy 'How hot!', atatáy 'How gross!', alaláy 'How surprising!', ayayáy 'How painful!'. In a sense, then, the regular stress pattern seen in members of all other word classes classifies them as non-interjections.

6. In addition to nominal usage, the plural affix is also used to mark plural on some verbs; specifically, as part of the 3rd person plural marker (-nkuna). It is optional and is used when plurality is not expressed on the subject or understood pragmatically. See further discussion below.

7. Schachter's orthography uses $h$ for /x/, while my practical EHQ orthography uses $j$.
} 
(3)
a. Rika-ška: hatun-(kuna)-ta
see-PTCP.1sG big-(PL)-ACC
'I saw (the/a) big one(s).'
b. Rika-ška: alkalde-(kuna)-ta
see-PTCP.1SG mayor-(PL)-ACC
'I saw (the) mayor(s).'

\begin{abstract}
Although number and case markers are indeed commonly used with nouns, it does not follow that any item they affix to is a potential noun phrase head (see below). The use of copular predication as evidence cited by Schachter is also unconvincing, since nominal and adjectival copular predicates can differ with respect to features like degree words, as discussed above for modifier constructions. These modified examples from Schachter illustrate the contrast by showing where degree words can be added and where they cannot:
\end{abstract}



Schachter's characterization of Quechua word classes also relies on examples of nouns acting as modifiers (NN). There are several different constructions in Quechua in which nouns are juxtaposed, including zero-copula predication in the 3rd person. When I sought grammaticality judgments for constructions like Schachter's proposed example of NN modification below in (5b) (chay alkalde runa), speakers of EHQ preferred a copular reading. This is in part because runa not only means 'man' but, in certain relevant contexts (like municipal politics, alluded to by 'mayor'), can also mean 'indigenous man/person'. Only when careful not to put a strong declarative phrasal stress on the penultimate syllable of runa can a 'that man who is mayor' reading be achieved over 'that mayor is an indigenous person'. This is in part because, unlike adjectival modification (AN), in Quechua the interpretation of nominal modification (NN) is not always semantically uniform (see below). By comparison, the example of a canonically-ordered adjective-noun phrase in (5a) (chay jatun runa) cannot achieve a copular interpretation except under highly restricted conditions, and is dispreferred by speakers with such a reading. These preference structures, illustrated below with modified examples from Schachter, begin to reveal some further differences between Quechua nouns and adjectives: 


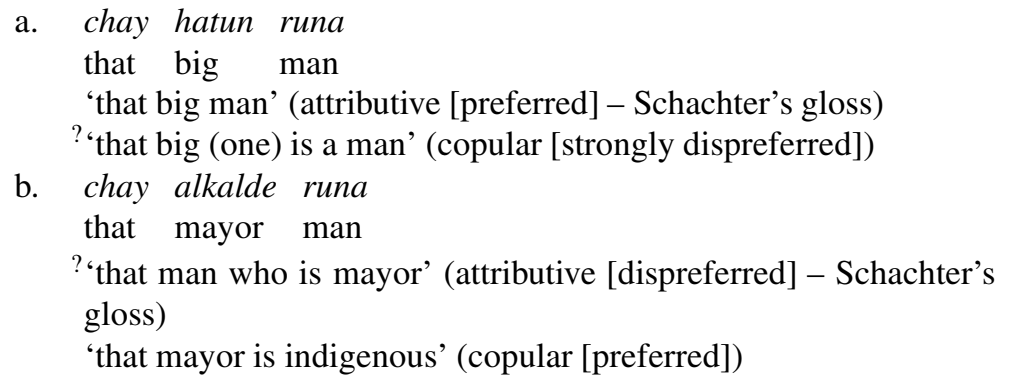

A number of linguists have pointed out problems with Schachter's account of Quechua, including Croft (2001: 66-69) and Beck (2002: 99-101, 140-149). Using sources on Peruvian Quechua, Beck came to many of the same conclusions that I have arrived at using my data from $\mathrm{EHQ}$, specifically concerning compounding $(\mathrm{NN})$ versus adjectival modification (AN) and the restriction of adjective-headed noun phrases to cases when elliptical noun heads are available pragmatically (Beck 2002: 99-159), topics I will discuss in detail below.

Despite these critiques in the literature, Quechua has continued to be cited as representative of a crosslinguistic "type" that is "flexible" with respect to nouns and adjectives (specifically "type 2": Hengeveld 2007, Hengeveld \& van Lier 2008: 766; Smit 2007: 59; Gómez Rendón 2008, etc.; Schachter \& Shopen 2007). ${ }^{8}$ This article supports and builds on those earlier critiques in hopes of establishing a better account of Quechua word classes by showing that EHQ does in fact distinguish word classes appropriately labeled "noun" and "adjective". ${ }^{9}$ The first line of evidence I will discuss concerns patterns of modification within the noun phrase.

8. Some of these accounts explicitly reject all criteria except for those based on morphosyntax, like this account of EHQ: "(I)t is not relevant that lexemes [...] are context-dependent, but that they occupy the syntactic position of referential heads without further measures and take nominal morphology (e.g., accusative markers). [...] The arguments against the classification of Quichua as a flexible language are insufficient. I propose therefore to classify Quichua as a language which makes no distinction between nouns, adjectives and adverbs [...] (I)t is clear that lexical flexibility is characteristic of Quechua and thus must be considered one of its intrinsic typological features" (Gómez Rendón 2008: 190-191). It is not clear on what grounds this approach discards many potentially interesting types of criteria, but even this narrow approach does not hold up (see discussions of "nominal" morphology and NP heads).

9. While Quechuan nouns and adjectives share features with classes of the same names in other languages, they are in some ways unique to Quechua (Haspelmath 2007). To recognize this problem, here I use the terms in quotes when referring to the crosslinguistic category concept, and otherwise refer to the language-internal word class. 


\section{Nominal versus adjectival modification}

\subsection{Compound construction types}

This section uses evidence from my EHQ corpus to consider the proposal that Quechua nouns and adjectives, as a single category, can freely modify each other (AN, NN, AA, NA). This proposal fails to systematically apply across the different construction types represented in the data. I found many cases of nouns modifying other nouns to create NN noun phrases, although semantically such modification is not attributive in the same sense that canonical adjectives like 'big' or 'yellow' are. Instead, it communicates specific kinds of relationships between nominals. The data supports an analysis of such noun phrases as compounds, showing how these compounds further divide into a number of semantic sub-types similar to those that have been studied for English compounds (Warren 1987 and many later sources).

A common type of compounding, both in Quechua and in English, indicates the material an object is composed of or constructed from, as in the terms allpa manka 'earth/clay pot', kaspi wasi 'stick/wood house', uksha techo 'grass roof', and cemento wasi 'cement house' seen in examples (6a, b): ${ }^{10}$

$$
\begin{aligned}
& \text { a. Allpa manka ka-shka ni-n chay-ka. } \\
& \text { earth/clay pot be-PTCP say-3sG that-FOC } \\
& \text { 'It was a clay pot, they say, that one.' } \\
& \text { b. Chay-manta ka-rka kaspi wasi. Kaspi, uksha, } \\
& \text { DM.DST-ABL be-PST wood/stick house. wood grass } \\
& \text { uksha techo. Pero kunan yapa cemento wasi tiya-n. } \\
& \text { grass roof but now more cement house exist-3sG } \\
& \text { 'From then it was (all) wood house(s). Wood, grass, grass roof. } \\
& \text { But now there are more cement house(s).' }
\end{aligned}
$$

The semantics of the "composed of" construction type differ from those of other types, as in the following example (7). Here "composed of" constructions kaspi telar 'wood loom' and fierro telar 'metal loom' contrast with a second construction type represented by maki telar 'hand loom'; obviously this loom is not composed of hands, but is rather operated by them.

10. One reviewer suggested the terminology "classifying modifiers" for some of these constructions as a special intermediate kind of modification that further specifies its head noun without being fully productive either as adjectival attribution or nominal compounding. However it seems that an approach based on construction sub-types and potential conventionalizations of specific head/modifier pairs makes this terminology unnecessary for the current discussion, while not necessarily contradicting the insight it reflects. 


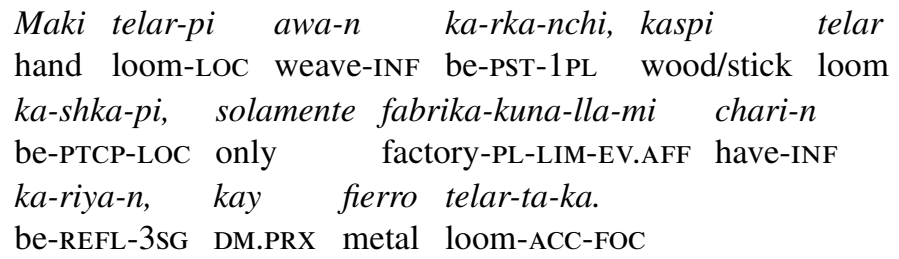

'We had to weave on hand looms, as they were wood looms; only just the factories have them, these metal looms.'

As illustrated in the example above, the same nouns can occur as part of "composed of" modification as well as "for use with" modification, as long as there is a viable interpretation. Adjectival modification in EHQ shows a different pattern, so that jatun telar cannot have the improbable meaning 'loom made of big (ones)' or 'loom for use by big (ones)', but must necessarily be 'loom with the attribute "big"'. Phonological features of compounding are not particularly prominent in EHQ, but a few very frequent compounds do constitute a single phonological word. One example is the term yakuishpa, which combines the disyllabic words yaku 'water' and ishpa, a root referring to 'urine', into a single trisyllabic word that is the common term for 'urine': ${ }^{11}$

(8) Chay-wan, yaku-ishpa-wan yanu-shpa, kimsa puncha-ta DM.DST-COM water-urine-com cook-SR three day-ACC malla-chi-rka.

wash-CAUS-PST

'With that, cooking [the medicinal plant] with water-urine, for three days I made him wash (applying it; to cure a rash).'

Other compounds that occur relatively frequently in conventional combinations include names of specific species of flora and fauna constructed from two nouns, e.g., nina kuru 'firefly', aya kallanpa 'spirit mushroom', and kuychi anku 'rainbow vine':

a. Nina kuru riksi-nki?

fire worm know-2sG

'Are you familiar with fireflie(s)?'

11. The difference in meaning between the simple form ishpa and the compound yakuishpa is unclear - the second term is generally more common in the Imbabura variety, but both terms can be used to refer to 'urine'. One possibility is that this term is a calque from a pre-Quechuan language from the Barbacoan family, as some Barbacoan languages use a multi-root term for 'urine', one of the roots being 'water'. This is speculative, however, and there is some counterevidence (such as word order, as 'water' should be the second root). 
b. Ari kay-pi-pash, tiya-n-mi, imashti-mi, yes DM.PRX-LOC-also exist-3sG-EV.AFF what.name-EV.AFF aya kallanpa ni-n. ghost/spirit mushroom say-3sG

'Yes, here as well, it exists, whatchamacallit, "spirit mushroom" they say.'

c. Kuychi anku tiya-n chay-pi. rainbow vine exist-3SG DM.DST-LOC

'Rainbow vine exists there.'

Unlike the productive attributive modification found in most AN constructions, NN constructions often have conventionalized meanings associated with that specific pair. ${ }^{12}$ The 'rainbow vine' in (9c) is not a 'vine with a rainbow-like quality' but is rather a medicinal vine used for making a urine-based topical solution for treating a skin rash caused by close encounters with rainbows, which are malevolent forces for many Andean people.

Nouns used to modify usually undergo significant semantic changes, so that while nouns like urku 'mountain' and sacha 'forest' shown in (10a, b) follow a productive pattern of modification, as modifiers they do not have adjectival meanings directly derived from the semantics of the root ('mountainous', 'forested', etc.) but rather have an idiomatic meaning of 'wild':
a. Shuk cabo ra-shka nin,
sacha anku-manta.
one rope do-PTCP say-3sg forest vine-ABL
'He made a rope, they say, from a (wild) "forest" vine.'

12. Quechua adjectives can also sometimes occur in conventionalized compounds, similarly to the English redwood versus red wood. For example, the word shimi, meaning 'mouth; word; language' here appears with a typical adjectival modification: alli shimi-kuna-ta-lla [good word-PL-COM-LIM] 'just good words'; in other contexts AN phrases have specific conventional meanings, such as when shimi is modified by the adjective yanka meaning 'common; free; worthless'; for speakers of the Imbabura variety, yanka shimi or 'common language' is a conventionalized term for Quechua. The variety of conventionalized meanings available to $\mathrm{AN}$ and $\mathrm{NN}$ combinations is very large. In the following example, the compound tayta mama [father mother] does not really feature modifying semantics, but rather shows some kind of coordinate compounding to arrive at the meaning 'parents', and as such can be both pluralized and be modified by an adjective: Jatun [tayta mama]-kuna-man [big father mother-PL-ALL] 'to the big (important) parents'. This form is similar to what has been called a "dyadic" kinship term, perhaps with some aspects of an "additive co-compound" (Evans 2006). Such specific pairs are best analyzed as constructions with both productive and conventionalized dimensions. 
b. Pay-ka urku taruka ni-shka, kunu, urku 3sG-FOC mountain deer say-PTCP rabbit mountain

kunu ni-shka.

rabbit say-PTCP

'That's called a (wild) "mountain" deer, rabbit, called a (wild) "mountain" rabbit.'

Different from the "composed of" and "for use by" constructions and from the flora and fauna names cited above, these compounds are based on something like an "inhabitor of" construction. The deer in ( $10 \mathrm{~b})$ is not "composed of mountains' or 'for use by mountains' but rather is an 'inhabitor of mountains', and, according to the specific idiomatic meaning, is 'wild'.

\subsection{Conventionalized compounds and the adjective class}

Another kind of NN modification was noted by most early Quechua grammarians in their discussions of "gender" marking (Santo Tomás 1560 [1993: 22], Huerta 1616 [1993: 21], Cordero 1892 [1992: xxv-xxviii]), which is pervasive in Spanish but which in Quechua shows none of the agreement patterns known from the Romance languages - patterns that make it possible to easily identify noun phrase heads and modifiers on morphological grounds (even when the head is elliptical, the modifier agrees with its gender; see discussion on noun phrase head ellipsis below). Quechua has no grammatical gender in the sense that Spanish does, but rather employs a specific NN modification type using 'woman' and 'man' as modifiers of animate nouns with a "gender of" meaning.

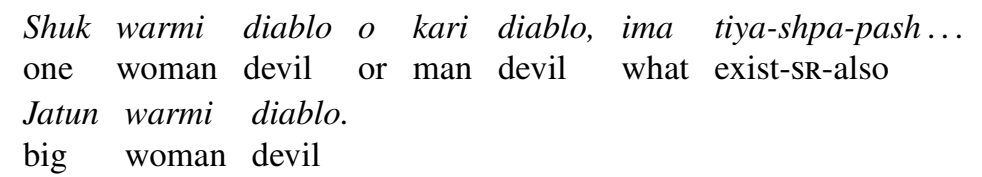

'A female devil or a male devil, whatever it was ... a big female devil.'

The contrast between this kind of compounding and true adjectival modification is nicely illustrated by the second line of (11). The adjective jatun 'big' has scope across the entire compound warmi diablo 'female devil' while the opposite order (*warmi jatun diablo) is ungrammatical (see (13b) below). A similar kind of modification marks both gender and age of modified animate nouns in $\mathrm{NN}$ compounds like paya mama [old.woman mother] and ruku tayta [old.man father] ${ }^{13}$ Another NN compound type uses the word for 'baby', wawa, to mark age neutrally of gender.

13. The term ruku 'old man' has also grammaticalized as an augmentative marker when occurring after an adjective: jatun-ruku [big-AUG], shinchi-ruku [strong-AUG]. This usage can be 


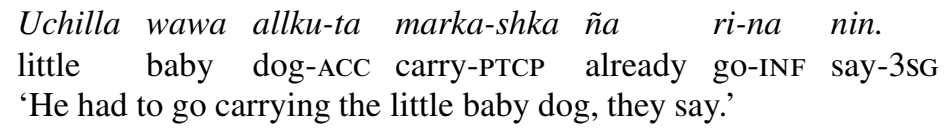

Like (11), (12) shows a NN compound modified by an adjective with scope across the compound; $[\mathrm{A}[\mathrm{NN}]]$ attributive constructions like this are common, while $*[\mathrm{~N}[\mathrm{AN}]]$ and $*[[\mathrm{AN}] \mathrm{N}]$ are not attributive and are for most purposes ungrammatical (although they might sometimes achieve a possessive reading, which is not compounding, strictly speaking; see below). None of the specific semantic relationships of compounds can be maintained if the modifying/modified nouns are not adjacent to each other. Inverse modifier order results in ungrammaticality (*NAN):
a. "age of"
*wawa uchilla allku
baby little $\operatorname{dog}$
b. "gender of"
*warmi jatun diablo
woman big devil
c. flora/fauna name
*nina yurak kuru
fire white fly
d. "constructed from"
*kaspi uchilla telar
wood little loom
e. "for use by"
"maki uchilla telar
hand little loom

In multiple-modifier constructions syntax is restricted by lexical class membership, so that adjectives occur to the far left with a rightward scope over the noun phrase, while nominal modifiers must occur adjacent to the noun they compound with. Multiple stacked adjectives, on the other hand, may sometimes have preferred orders, but are generally interchangeable (while nouns cannot usually stack at all):

distinguished on several levels: morphosyntactically, as they are not complete noun phrases (AN); semantically, because they are not 'big old man' or 'strong old man' but rather 'really big' and 'really strong'; phonologically, because the augmentative jatun-ruku takes on some of the characteristics of a single phonological word (jatun ruku as two separate phonological words does indeed mean 'big old man'). 
a. preferred

jatun yurak wasi

big white house

b. somewhat dispreferred ${ }^{14}$

yurak jatun wasi

white big house

Some patterns of NN modification in EHQ resemble possessive constructions, since possessives can be formed either with overt morphology or by simple juxtaposition. Some examples, such as (15), show similar meanings with or without the possessive suffix -pak. It is important to note that adjectives, in a similar modifier position, cannot modify with the possessive suffix, showing a clear morphological distinction from nouns.

$$
\begin{aligned}
& \text { shuk jatun kiru(-pak) rama-pi } \\
& \text { one big tree(-POSs) branch-LOC } \\
& \text { 'on a big tree(-'s) branch' }
\end{aligned}
$$

The same nouns can occur in different compound and possessive construction types with different meanings. While "man" and "woman" are often used as modifiers in "gender of" constructions, as mentioned above in (11), in other contexts as in (16) the same nouns can only achieve a possessive reading.

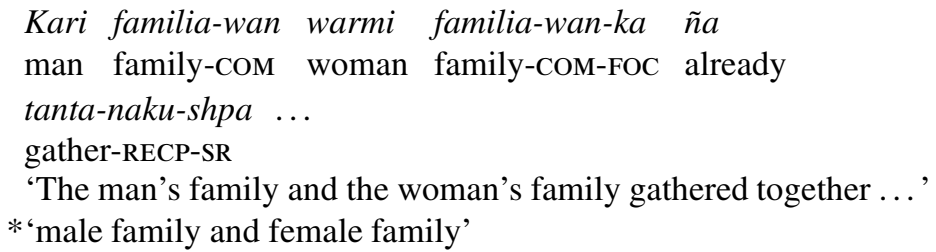

With overt possessive morphology (kari-pak, warmi-pak) the above example's meaning would not be significantly altered. ${ }^{15}$ Without overt morphology, disambiguation between possessive and "gender of" constructions must rely on the semantic and pragmatic context rather than on simply the NN syntax of the noun phrase. Frequently the distinction between possessives and compounds is blurry; the examples $(17 \mathrm{a}, \mathrm{b})$ work with either reading:

14. The difference between these two orders appears to reflect a general "size before color" preference, but one that interacts with information structure: the second order could be used contrastively for comparing multiple big houses of different colors, for example.

15. There is sometimes a difference in terms of definiteness of the head noun in these two construction types: the more compound-like NN would be the indefinite ('tree branch; branch of a tree') while the overt possessive N-POss $\mathrm{N}$ would be the definite ('the tree's branch'). 
a. Chay tigre uma-ta apa-ri-shka...

DM.DST tiger head-ACC take-REFL-PTCP

'Carrying that tiger head / tiger's head ...'

b. Iglesia punku-pi shaya-shpa-ka...

church door-LOC stand-SR-FOC

'Standing at the church door / church's door ...'

The distinctions between compounds, possessive constructions and other kinds of modifier constructions are important to consider in any account that describes Quechua nouns and adjectives as "flexible", since such an account is based on the idea that noun-noun (NN) modification is adjective-like, in that it is attributive ( $\mathrm{NN}=\mathrm{AN}$ ?). A problem for the "flexible" analysis is that the data do not show primarily attributive semantics but rather show different kinds of compounding and possessive constructions, which are examples of modification between nominals $(\mathrm{NN})$.

To summarize this section, the juxtaposition of nouns ${ }^{16}$ is one of the most important devices in EHQ for many kinds of syntactic functions, yet the evidence does not support the idea that $\mathrm{NN}$ combinations are comparable to attributive adjectival constructions (AN) on all levels. When both compounding and attribution appear in the same noun phrase, the adjective's restricted place at the far left of the phrase clearly shows this distinction (ANN, *NAN), and the different semantic types and idiosyncratic conventionalizations seen in compounding also show a sharp contrast with the more uniform semantics of adjectival attribution. Considering these details with respect to Quechua word classes, it is clear that neither nouns nor adjectives can exhaustively duplicate the other class' behavior as a modifier.

\section{Morphology associated with nouns}

\subsection{Number and plurality}

In addition to the modification properties of the noun phrase, another argument for the "flexibility" of Quechua nouns and adjectives is that adjectives can apparently receive "nominal" morphology. While in certain contexts Quechua adjectives do take marking such as plural and accusative case, the usage of these morphemes can be quite broad, and they can occur outside of contexts

16. By extension, this covers the juxtaposition of any nominalized forms. Nominalized verbs in their "infinitive" form also readily modify nouns, often with a "of doing V" construction which is highly productive. For example: Chay pampa-na puesto-man [DM.DST bury-INF place-ALL] 'towards that place of burying' ('burial ground'). I am unable to fully address the word class status of derived nominals here, but like underived forms, derived forms also show some degree of word class overlap and, in some cases, conventionalized meanings associated with cases of multi-class membership. 
generally thought of as noun phrases. To define the noun class as consisting of words that occur with "nominal" morphology and then to define such morphology as "nominal" based on its common occurrence with nouns would be circular.

When number and gender marking occur on Spanish adjectives, this is not considered evidence that they are nouns, but rather is understood as agreement. In Quechua number marking is optional in many contexts, but when it does occur on an adjective it might also be thought of as at least co-referential to a proximate nominal discourse referent, if not as grammatically agreeing with it. Some usages of plural marking with adjectives in EHQ are in fact not very different from usages seen in languages that are generally considered to have distinct "adjective" classes, such as the case of Spanish adjectives which agree in number with nouns that they modify in the noun phrase or through copular constructions. Compare these similar examples in Spanish (overt copula) and EHQ (zero copula/adjectival predicate):
a. $\operatorname{Los}$
pariente-s de mi
esposo son bueno-s. ART-PL relative-PL of 1 sG.POss husband be.3PL good-PL 'My husband's relatives are good (people).' [number agreement marked four times]
b. $\tilde{N} u k a$ kusa-pa familia-kuna-ka alli-kuna-ma 1sG husband-POss family-PL-FOC good-PL-EV.AFF 'My husband's relatives are good.' [number co-reference marked two times]

While EHQ does not have obligatory agreement like Spanish, adjectives can optionally show kinds of plural-marking correspondences with the nouns they co-refer to. ${ }^{17}$ The same plural suffix is used for some kinds of verbal number agreement as well. The EHQ plural suffix communicates the value of number over several different word classes, and so it is not a good diagnostic for noun class membership.

\subsection{Case marking and the diverse uses of the "accusative"}

Like the plural suffix, the "accusative" suffix has broad usage patterns that are not exclusively "nominal", yet the occurrence of this suffix (-ta) with adjectives is a commonly-cited piece of evidence for their "nominal" status. The suffix - $t a$ marks a number of different associations with both transitive and intransitive verbs, including direct and indirect objects as well as beneficiaries,

17. Another similar example shows the adjective sinchi 'strong' agreeing in number with a noun in a copular construction: Punta gente-kuna sinchi-kuna ka-rka n-in [first people-PL strong-PL be-PST say-3sG] 'In earlier times the people were strong, they say'. 
goals, routes of motion verbs, and some adverbial modifiers. Here the suffix appears multiple times with different meanings within the same construction, where it marks both an object and an oblique or "malefactive":

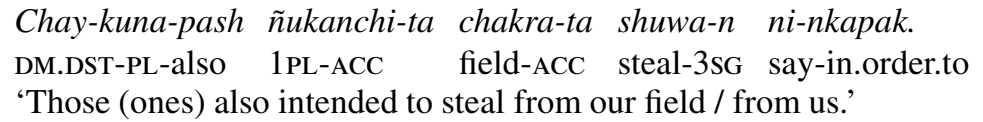

Such double marking is common in languages without distinct datives (a "primary object" pattern: Guerrero \& Van Valin 2004; also Blake 2001: 103). The particular relation to the verb that - $t a$ marks is in part determined by the word class of the constituent it occurs with, making it not a good diagnostic for class membership by itself. Here it occurs not marking objects but rather paths or goals of motion verbs, e.g., may-ta 'where' and casta-ta 'to the coast' in (20).

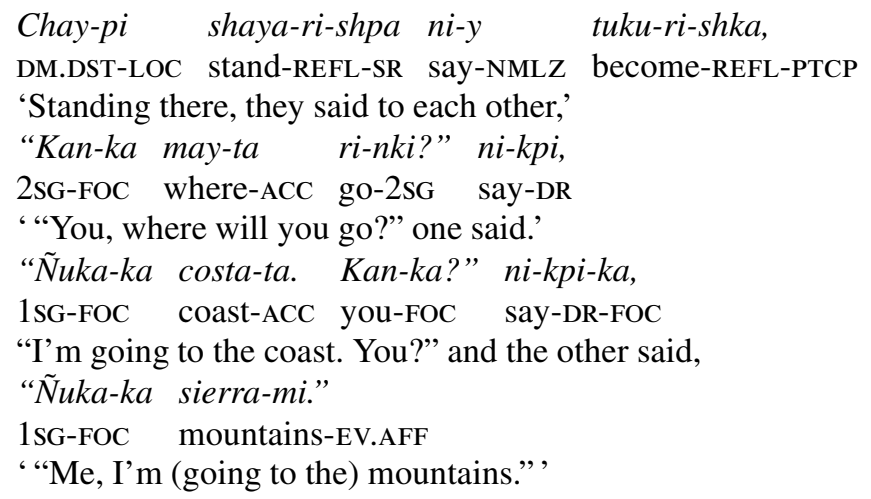

Some of the recipients of - $t a$ in motion verb constructions are clearly not nouns, including spatial terms such as jawa 'up' in (21). Here the suffix marks an adverbial modifier. $^{18}$



Adverbial uses of -ta are common, and extend to temporal adverbs as well:

18. Hastings (2003: 39) brings up the possibility that - $t a$ is an "unselective binder" in that it marks some kind of underspecified relationship with the verb rather than "accusativity" specifically. Although Hastings does not ultimately opt for this account, it is worth considering. It is probable that $-t a$ is basically accusative, but has been extended to mark other kinds of relationships having to do with the structure of the VP. 

Unay-ta
illa-shka ka-rka.
long(time.period)-ACC lack-PTCP be-PST
'(It) was lacking for a long time.' or ' 'It long had lacked.'

It is unnecessary to analyze the temporal adverb unay in (22) as a nominal object, despite its "accusative" marking. The same is true for 'a little bit' in (23):
Asha-lla-ku-ta
shuya-y.
little(quantity)-LIM-DIM-ACC wait-IMP
'Wait just a little bit.'

When -ta occurs on nouns together with transitive verbs it is likely that they will be interpreted as objects and obliques; when it occurs on nouns with intransitive motion verbs they will be interpreted as goals and paths; when it occurs on adverbs or adjectives, it can mark a verb modifier relationship. In these examples where -ta occurs twice in the same construction the nature of its meaning changes depending on whether it occurs on nouns or adverbs or adjectives.

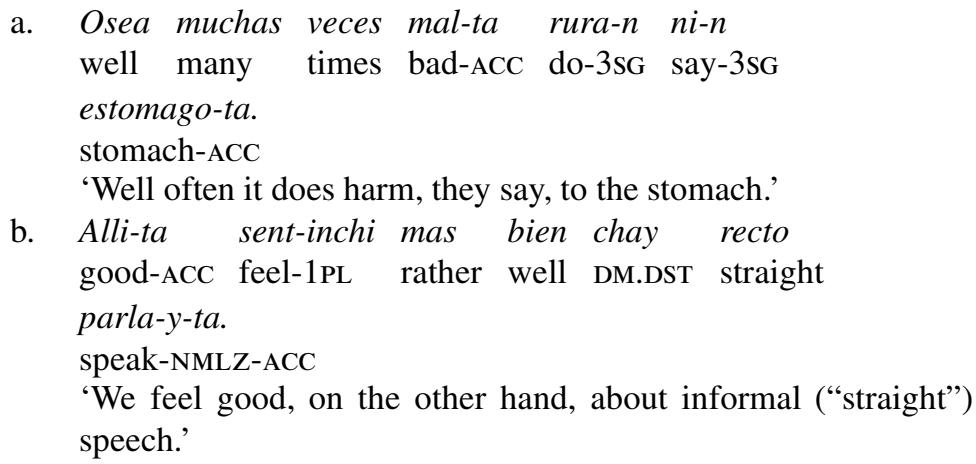

Because of this variability in meaning of "accusative" marking in EHQ, the occurrence of this suffix alone should not be considered a clear measurement of noun class status, because word class partially changes its meaning, determining whether it is truly accusative or whether it instead marks some other kind of relation to the verb.

\section{Word classes and their overlaps}

4.1. Overlaps among nouns, adjectives, and verbs

The last major argument in support of a "flexible" categorization of Quechua word classes is based on the claim that Quechua adjectives have the syntactic property of being able to head noun phrases. A close look at examples from 
EHQ does indeed reveal that some adjectives occur in such a syntactic position, but also reveals that such usages are neither uniform nor are they exhaustive across the adjective class. Furthermore, word class overlaps in EHQ not only exist between nouns and adjectives, but are frequent among all the major word classes, and a number of adjectives can occur not only as nouns and nominal modifiers but also as verb roots and verb modifiers (see below). This section looks in detail at "nominal" uses of adjectives and related category overlaps.

An analysis of Quechua adjectives as noun phrase heads actually conflates two different phenomena: (i) most adjectives can only head noun phrases under restricted conditions (when an elliptical nominal head is available anaphorically), but (ii) a number of specific adjectives have acquired conventionalized nominal meanings that allow them to head noun phrases without restrictions. For example, the adjective uchilla, or 'little', in the absence of any overt nominal head or likely candidate for anaphoric reference, has the conventional meaning of 'child' (like in English little ones), and as such can occur in any nominal morphosyntactic context without restriction. In (25) uchilla heads a noun phrase and takes plural and "accusative" morphology; on the other hand, the adjective jatun 'big' has no such conventional interpretation (like 'adult', from 'big ones'), and as such cannot generally head noun phrases.

$$
\begin{array}{llll}
\text { a. Jaku puñu-shun } & n i-s h k a & n i-n \\
\text { let's.go sleep-1PL.FUT } & \text { say-PTCP } & \text { say-3sG } \\
\text { uchilla-kuna-ta-ka. } & &
\end{array}
$$

little-PL-ACC-FOC

'Let's go sleep, they say that he said, to the children.'

b. Jaku puñu-shun ni-shka nin jatun-kuna-ta-ka. let's.go sleep-1PL.FUT say-PTCP say-PTCP big-PL-ACC-FOC

*'Let's go sleep they say that he said, to the adults.'

'Let's go sleep they say that he said, to the big ones.' [no convention; seeks anaphoric referent]

Generally Quechua adjectives pattern like jatun, which only heads noun phrases when an elliptical modified noun is available anaphorically, rather than like uchilla, with its conventional nominal semantics and unrestricted nominal morphosyntax. ${ }^{19}$ While a set of canonical nouns, verbs, and adjectives in Quechua show the features of just one category membership, when delineating the general pattern for canonical adjectives it must be noted that Quechua shows many cases like uchilla that have specific lexical semantics of more than one word class. These overlaps are idiosyncratic, so that one item may be used

19. If an interpretation of uchilla as 'child' does not make sense in a given context, the same restrictions apply as with other adjectives. 
nominally and verbally, but not adjectivally, other items may be used adjectivally and nominally, but not verbally, and others may be used in all three classes. In some cases it is possible to identify a probable original class membership that was extended to other classes, like uchilla which is primarily an adjective but has been extended to nominal use. In other cases where a lexical item belongs to several different classes it can be difficult to know which one is its original or primary membership and which are extensions. For example, the root llaki can occur nominally ${ }^{20}$ (26a), verbally (26c), AND adjectivally/ adverbially (26b):
a. Chay kipa cha-shna-lla-ta jatun llaki-ta; DM.DST after DM.DST-SEM-LIM-ACC big sad-ACC pay-kuna-ka mancha-shka ... 3SG-PL-FOC scare-PTCP 'After that, (they experienced) a thing like that, a big sadness; they were scared ...'
b. Shina llaki-lla-ku puri-rk-ani, wawa-kuna-wan shina SEM sad-LIM-DIM walk-PST-1SG child-PL-COM SEM 'Like that, I walked around sadly, with (the) children, like that.'
c. Llaki-ku-ni. sad-PROG-1sG 'I am sad.'

A number of lexical items pattern similarly, including chiri, usually an adjective 'cold', but also a nominal 'coldness' and a verb 'to be cold'; (27) shows these last two uses:

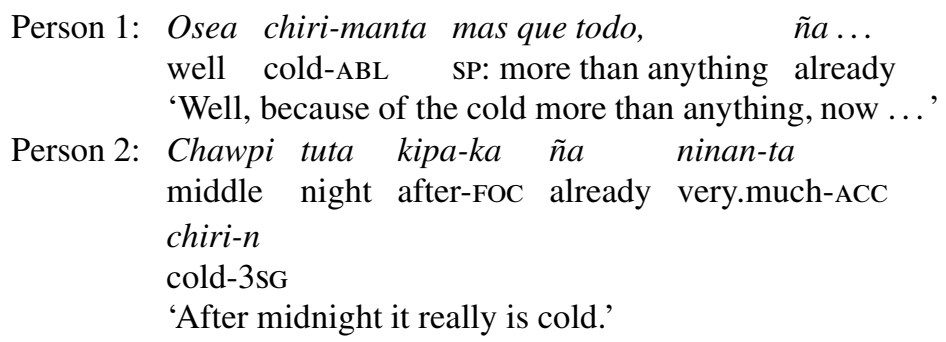

20. It is possible that in the cases of verb roots ending in /i/ the verb is (or once was) nominalized by the suffix $-y$; the similar place and articulation of the suffix with the final vowel of the root makes it difficult to detect in rapid speech; for some varieties and/or speakers it is unpronounced altogether. This process identifies a possible route by which a verb root with specific phonological characteristics can come to have conventional nominal or adjectival properties without requiring any derivational morphology. 
Other roots overlap between just two of these three word classes. For example, the adjective junda 'full' can modify as in junda killa 'full moon' or junda wiksa 'full stomach' ${ }^{21}$ and also occurs as a verb root junda-na 'to fill', but not as a noun (*'fullness' or *full thing'). A similar case is that of piña, which usually occurs as the verb 'to be/get angry' but sometimes occurs adjectivally, as in (28) where an adjectival predicate occurs with a degree word:

$$
\begin{aligned}
& \text { Chay soltera-ka achka piña, achka. } \\
& \text { that single.woman-Foc very angry very } \\
& \text { 'That single woman is very angry, very (much).' }
\end{aligned}
$$

The use of piña as a noun phrase head, however, shows the same restrictions as for more canonical adjectives. On the other hand, the noun ishpa 'urine' does not have any special adjectival meaning (although it might be used in a nominal compound), but is commonly used as a verb root 'to urinate'. Example (29) shows how this same lexical item is used both nominally, as the head of a compound, and verbally, as the main finite verb:

$$
\begin{aligned}
& \text { Chay-mi kuychi-mi ni-shpa-mi, } \\
& \text { DM.DST-EV.AFF rainbow-EV.AFF say-SR-EV.AFF } \\
& \text { 'That really is (because of) the rainbow, (so) saying,' } \\
& \tilde{n} a \quad \text { Mila-ka yaku-ishpa-wan, ñuk ishpa-rka-ni } \\
& \text { already Mila-FOC water-urine-COM 1SG urine-PST-1SG } \\
& \text { 'Mila (treated it) with urine, I urinated.' }
\end{aligned}
$$

A number of other lexical items show this kind of noun/verb overlap while at the same time they do not overlap with the adjective class, ${ }^{22}$ such as in (30) with kushni 'smoke'. This root is commonly used with verbal morphology with the meaning 'make smoke' but it cannot modify nouns to mean 'smoky' or anything of the sort.

$$
\begin{aligned}
& \text { Shuk chuklla wasi tiya-ku-shka ni-n, chay-ka } \\
& \text { one thatch house exist-PROG-PTCP say-3sG DM.DST-FOC } \\
& \text { kushni-ku-shka ni-n, } \\
& \text { smoke-PROG-PTCP say-3sG } \\
& \text { 'There was a thatch house, they say, and there it was smoking (smoke } \\
& \text { was coming out), they say.' }
\end{aligned}
$$

21. Junda wiksa 'full stomach' in some contexts has the double meaning 'pregnant'; how specific $\mathrm{AN}$ and NN constructions in discourse gain further idiomatic meanings beyond their basic compositional semantics is a topic for future investigation.

22. Another good example of a verb/noun but not adjective root is jambi 'cure' as in this example where it occurs both nominally and verbally: Chay botica jampi-kuna-wan na jampi-ri-rka$c h u$ [DM.DST pharmacy cure-PL-COM NEG cure-REFL-PST-NEG] 'With those pharmacy cures (medicines) it did not cure (the disease)'. Another example is razu: 'snow' or 'to snow'. 
Table 1. Single and multiple-class membership of Quechua roots

\begin{tabular}{|c|c|c|c|c|}
\hline & & Verb & Noun & Adjective \\
\hline \multirow[t]{2}{*}{ Canonical verbs } & shuya & 'to wait' & $*$ & $*$ \\
\hline & $n i$ & 'to say' & $*$ & $*$ \\
\hline \multirow[t]{2}{*}{ Canonical nouns } & ukucha & $*$ & 'mouse' & $*$ \\
\hline & punku & $*$ & 'door' & $*$ \\
\hline \multirow[t]{2}{*}{ Canonical adjectives } & jatun & $*$ & $*$ & 'big' \\
\hline & yurak & $*$ & $*$ & 'white' \\
\hline \multirow[t]{2}{*}{ Adjective/noun overlap } & uchilla & $*$ & 'child' & 'small' \\
\hline & mishki & $*$ & 'sugar' & 'sweet' \\
\hline \multirow[t]{2}{*}{ Verb/noun overlap } & ishpa & 'to urinate' & 'urine' & $*$ \\
\hline & kushni & 'to make smoke' & 'smoke' & $*$ \\
\hline \multirow[t]{2}{*}{ Verb/adjective overlap } & junda & 'to fill' & $*$ & 'full' \\
\hline & piña & 'to get angry' & * & 'angry' \\
\hline \multirow[t]{2}{*}{ Verb/noun/adjective overlap } & llaki & 'to be sad' & 'sad event' & 'sad' \\
\hline & chiri & 'to be cold' & 'coldness' & 'cold' \\
\hline
\end{tabular}

A classification of Quechua as a language "type" with two major open classes, verbs versus nouns/adjectives, emphasizes only the overlap between nouns and adjectives and ignores the overlap among all the major categories outlined in the examples above. These overlaps encompass most imaginable configurations throughout much of Quechua's lexicon, despite the fact that a number of lexical items also clearly pattern canonically as belonging to one and only one word class; see Table 1.

The highly idiosyncratic semantic changes that apply when roots belong to multiple word classes have to be approached almost on a case-by-case basis. Why is mishki a noun and an adjective but must be derived to be a verb, while ishpa and kushni are both underived verb roots and nouns, but are not adjectives? Some roots are primarily used as part of one class, but also have minor usages in other classes, like the root sisa, which is most frequently used as the noun 'flower' but around harvest time is often used in underived form with full verbal morphology as a verb 'to flower', describing the "flowering" of the crops. Speakers can creatively verbalize many nouns that infrequently occur as verbs, as on one occasion when a speaker of EHQ to my surprise accepted my example of a noun root wasi 'house', with verbal morphology in the sense of 'to go home'. While that specific usage was uncommon in my experience, such category extensions may originate in individual creative uses and eventually extend to more members of a speech community, establishing word class overlaps for individual roots. For this reason many of the specific category overlaps in EHQ exist on a local basis, and may not extend to all varieties or even to all speakers of the same variety - Table 1 is necessarily simplified across several 
different but closely-related dialects, glossing over some fine variation; other less closely-related varieties of Quechua may have experienced other histories leading to different kinds of overlaps. However, a preliminary survey of sources on different Quechuan varieties shows that many of the same multi-class overlaps exist throughout the family (see comparative Quechuan word lists in Beér \& Beér 2006 and Beér et al. 2006, etc.); a closer look at Quechuan historical linguistics would no doubt shed more light on how individual lexical items have extended their word class memberships over time.

\subsection{Modifiers and reduplication: Adjectives and adverbs}

The analysis represented in Table 1 is oversimplified in another way as well, as it focuses on just three word classes; overlaps are actually far broader and involve a number of minor categories and subcategories like adpositions, degree words, and numerals. I cannot address all of these overlaps here, but one of the most relevant concerns the distinction between adjectival and adverbial lexical items, which show some differences, but which also include many items such as alli 'well; good' that appear to be both adjectival, as in (31a), and adverbial, as $n(31 b):^{23}$

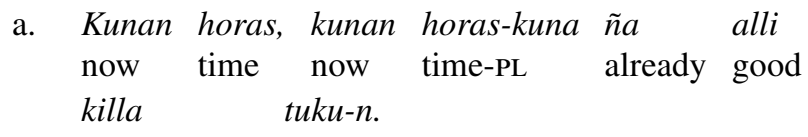

month/moon become-3sg

'Right now, right at this time, it is already becoming a good month.'

b. Chay-ka na alli porta-ri-shka ka-rka.

DM.DST-FOC NEG good behave-REF-PTCP be-PST

'That one had not behaved well.'

Adjectives and adverbs also share the property of reduplication for intensification, which contrasts these two word classes with all the other classes in the language. ${ }^{24}$ This is a case of adverbial reduplication, the word alli 'good; well' means 'very well' when reduplicated:

23. Another good example of such terms is sinchi 'strong; hard; difficult', which not only modifies nouns but frequently modifies verbs and occurs in copular constructions as well; for example: Karu puri-na ka-shpa sinchi ka-rka [far walk-INF be-SR be-PST] 'Having to walk far was hard'.

24. Hengeveld \& Rijkhoff (2005) cite some cases in which reduplication is the only major difference between subclasses of noun, and propose that reduplication alone is not sufficient to identify a separate adjective class. Here the evidence of reduplication is meant to be taken as one of many lines of evidence, and is by no means the sole distinction between nouns and adjectives. 
Similarly for adjectives, color terms like yana 'black', when reduplicated, mean that the color is stronger or more pervasive, as in example (33) in which the peas are said to be 'very black':

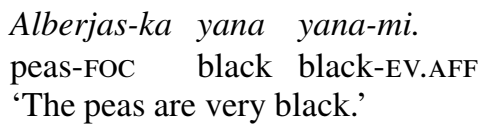

If these adjectival and adverbial modifiers were members of the nouns class we would expect to find nominal modifiers $(\mathrm{NN})$ also participating in this kind of productive reduplication as well, ${ }^{25}$ but aside from a few nouns with conventionalized adjectival meanings, nominal reduplication is unattested. One of the few nouns that can reduplicate for intensification is tullu 'bone' which has a conventionalized adjectival form does that not mean 'made of bone' or even 'bony', but rather means 'skinny':

$$
\begin{array}{llll}
\text { Kutin, } & \tilde{n} u k a-k a & \text { tullu tullu ka-shka-ni } & n i-n . \\
\text { again 1sG-FOC skinny skinny } & \text { be-PTCP-1sG } & \text { say-3sG } \\
\text { '(Then) again, I was very skinny, he says.' } &
\end{array}
$$

Nouns without conventionalized adjectival meanings, however, cannot reduplicate, so allku allku cannot mean 'very doglike' or anything of the sort. Neither can verb roots reduplicate in any context, so this feature provides a consistent test for distinguishing adjectives and adverbs from other word classes. This criterion would lump adjectives and adverbs together as a single "modifier" class. However, since a number of nominal modifiers (like jatun 'big') cannot freely modify verbs while a number of verbal modifiers (like allilla 'slowly') cannot freely modify nouns, there are also good grounds for splitting these classes.

\section{Adjectives as syntactic noun phrase heads}

\subsection{Can adjectives head noun phrases in the same way as nouns?}

In my data sample $93 \%$ of the adjectives were either noun modifiers or part of copular predicates. The remaining $7 \%$ headed noun phrases, but this number is inflated because a single lexical item accounted for almost half of these cases

25. A minor word class that can also reduplicate is the ideophone class; in this example tun occurs three times in succession: Ri-shka-lla-mi, tun tun tun yayku-nkapak [go-PTCP-LIM-EV.AFF tun tun tun enter-in.order.to] 'He had just gone, tun tun tun, in order to go inside'. Adjectives and adverbs reduplicate only once. 
- the word uchilla 'little', which has a conventional nominal meaning 'child', as discussed above. Without this word, adjectives in head position are less than $4 \%$ of the total number of adjectives in the sample. None of these were further modified by either nouns or adjectives, and all occur under restricted conditions, only when a nominal referent was clearly available anaphorically. For example, in (35) the terms 'black' and 'white' have the elliptical head camisa 'shirt':

$$
\begin{aligned}
& \text { Yana chura-shka, ña camisa o chay-pash yurak-lla. } \\
& \text { black put-PTCP already shirt or DM.DST-also white-LIM } \\
& \text { 'He/she put on a black (one), now a shirt, or also just a white (one).' }
\end{aligned}
$$

Because of their rareness in the data, I used elicitation as a way to further explore constructions with adjective-headed noun phrases. In sessions with speakers of the Cotopaxi and Imbabura dialects of EHQ I sought to confirm the restrictions suggested by the natural speech data, testing whether adjectiveheaded noun phrases only occur when an anaphoric referent is available. Speakers were asked to judge the grammaticality of constructed EHQ sentences and to translate them into Spanish. All speakers found the use of adjectives as heads of object noun phrases to be highly awkward. Even so, they were able to produce translations into Spanish, a language which, like Quechua, also allows adjectives to head noun phrases in some restricted contexts.

$$
\begin{array}{lll}
\text { Chay-pi shuk yurak-ta riku-ni. } \\
\text { DM.DST-LOC one white-ACC } & \text { see-1sG } \\
\text { Spanish: 'Allí veo un blanco.' } & \\
\text { 'There I see a white (one).' }
\end{array}
$$

In contrast, for examples like (36) if a context was supplied for the speaker such as "Imagine you are standing in front of several houses of different colors" the phrase immediately became less ambiguous. In Spanish it is easier to observe how the elliptical head noun relates to the adjective because the adjective must agree with the noun's gender, if a Spanish translation of example (36) in Spanish were referring to houses the adjective would change from blanc-o to blanc- $a$ in agreement with the feminine gender of the noun casa 'house'. EHQ does not have grammatical gender, ${ }^{26}$ but otherwise is comparable to Spanish in that an adjective used as head of a noun phrase will trigger a search for an

26. As discussed in previous sections, number "agreement" is possible in both languages, but is often optional in Quechua while it is obligatory and constitutes true grammatical agreement in Spanish. 
anaphoric referent to assign as head noun. ${ }^{27}$ While unattested in the discourse sample, the same should be true for noun phrases consisting of two adjectives (AA). When I tested such constructions through elicitation, results were similar to those seen with single-adjective noun phrases (A); consultants found them highly awkward unless a context was suggested to provide them with a nominal referent. In addition, changing the order of AA noun phrases as in (37), while sometimes identifying different preference orders (COLOR before SIZE - see above), did not significantly change the meaning, since both adjectives modify the same elliptical nominal head.

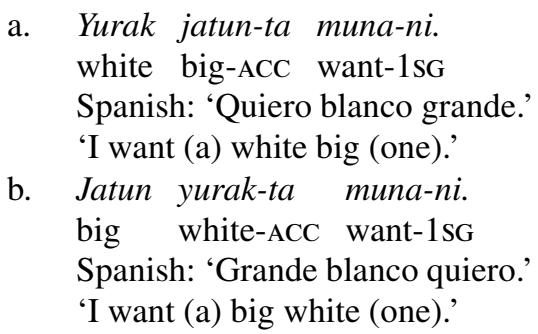

a. Yurak jatun-ta muna-ni.

white big-ACC want-1sG

Spanish: 'Quiero blanco grande.'

'I want (a) white big (one).'

b. Jatun yurak-ta muna-ni.

big white-ACC want-1sG

Spanish: 'Grande blanco quiero.'

'I want (a) big white (one).'

It is unclear here whether there is any reason to call the right-most adjective in (37) the "head" when it and its modifier are interchangeable. Phonologically, contrastive stress can distinguish "a white one among big ones of different colors" versus "a big one among white ones of different sizes", but in any case, the adjectives do not modify each other in either order, but rather modify some other salient nominal referent (AA[elliptical-N]). ${ }^{28}$

\subsection{The interaction of head-modifier order and word class membership}

The final set of examples I tested via elicitation are important for understanding the distinction between Quechua nouns and adjectives at the interface of lexical semantics and syntactic position. In example (37) above, changing the

27. I also did elicitation tests with a speaker of Peruvian Quechua from Ancash. While the varieties are very different phonologically, lexically and grammatically, they pattern similarly with respect to these constructions. The speaker agreed that this example was difficult to accept without an anaphoric referent:

(i) Tsay-chaw huk yuraq-ta rika-a.

there-LOC one white-ACC see-1sG

Spanish: 'Allí veo un blanco.'

'I see a white (one).'

28. Overt head nouns can take multiple stacked adjectives - three or more are accepted in elicitation, but this is rare in natural speech. The fact that modifying nouns cannot be stacked in the same way is another piece of evidence for distinguishing the two word classes. 
order of the two adjectives (AA) did not result in ungrammaticality. However, in canonical adjectival modifier noun phrases (AN) changing the order of the two words does result in ungrammaticality, because it attempts to force a modifier into a head role - triggering a search for an anaphoric referent - while attempting nominal (compound-type) modification of adjectives, which cannot be modified in this way (*NA). Speakers of both the Cotopaxi and Imbabura dialects translated the example in (38) of a canonical AN noun phrase to Spanish similarly, using the modifier phrase 'white house'.

$$
\begin{array}{lll}
\text { Chay-pi shuk yurak wasi-ta riku-ku-ni. } \\
\text { DM.DST-LOC one white house-ACC } & \text { see-PROG-1sG } \\
\text { Spanish: 'Allí veo una casa blanca.' } & \\
\text { 'There I see a white house.' }
\end{array}
$$

In comparison, the opposite order was generally judged ungrammatical.

$$
\begin{aligned}
& \text { *Chay-pi shuk wasi yurak-ta riku-ku-ni. } \\
& \text { DM.DST-LOC one house white-ACC } \\
& \text { *'Thee-PROG-1sG } \\
& \text { I see a house-like white (one).' }
\end{aligned}
$$

Interestingly, a few speakers, after some thought and hesitation, were able to force interpretations of sentences like (39), but in those cases word class membership overrode Quechua's modifier-head syntactic order, as speakers always offered the Spanish noun phrase casa blanca, headed by 'house', regardless of word order, and not the improbable alternative 'house-like white (one)'. It is possible that in some of these cases speakers parsed the example as two separate sentences - in those cases an adjective-headed noun phrase need only search as far as the previous sentence for a salient nominal referent as its semantic head. In fact, by purposefully adding a pause between the two phrases, one can achieve precisely this reading, as in (40):

$$
\begin{aligned}
& \text { Chay-pi shuk wasi. - } \quad \text { Yurak-ta riku-ku-ni. } \\
& \text { DM.DST-LOC one house [pause] white-ACC } \\
& \text { 'Thee-PROG-1sG } \\
& \text { '(s) a house. I see a white (house).' }
\end{aligned}
$$

The elicitation examples above help to confirm a few facts about word classes in EHQ. First, similarities among nouns and adjectives are not bidirectional (see Evans \& Osada's criteria, 2005: 375), so while nouns can modify nouns and be modified by nouns in compounds ( $\mathrm{NN}$ ), adjectives can only modify nouns (AN), and can never be modified by nouns (*NA). And second, noun phrases consisting of one or more adjectives and no overt nouns (A, AA), while not ungrammatical in a strict sense, are only acceptable under the restricted pragmatic condition of anaphoric access to a nominal referent, a restriction that does not apply to nouns. 


\subsection{An exercise designed to predict adjective-headed elliptical noun phrases}

As reflected in the examples in the previous section, when the semantic properties of a word's class membership status come into tension with its morphosyntactic position, as in cases in which an adjective occurs as the head of a noun phrase rather than its modifier, speakers and listeners will often look for a possible context for ellipsis rather than rejecting the utterance outright. If a likely anaphoric nominal head is available pragmatically, then that referent will be assigned as the elliptical head of the noun phrase, but if not, the construction will become, if not completely "ungrammatical", at least underspecified for any meaningful interpretation. Accounts of a single noun-adjective class in Quechua have ignored this highly regular pattern of pragmatic restrictions on the potential grammaticality of adjective-headed noun phrases as compared to noun-headed noun phrases. Nouns are not under any pragmatic restrictions with respect to the possibility of their heading noun phrases, while adjectives were rejected as noun phrase heads unless a suitable context was supplied.

The low frequency of adjective-headed noun phrases in my corpus correlates well with the observation that such constructions occur only under specific pragmatic constraints. However, this tells us little about cases when the constraints are satisfied, such as when an obvious anaphoric nominal head is available, as these cases were rare in the corpus. If my account is accurate it should be possible to predict when such constructions are viable by designing a controlled pragmatic context, providing speakers with an obvious anaphoric referent and thus creating a setting in which elliptical-head noun phrases are likely. Of course, even with the availability of an elliptical nominal referent, the speaker always has the option of producing the full (AN) noun phrase. Yet there are strong reasons why, given the option, speakers would be likely to choose the elliptical phrase (A). From the standpoint of pragmatics, the preference structures referred to by the Gricean "maxim of quantity" motivate speakers to say only as much as necessary - so that, once a discourse referent is established, it is redundant to keep re-stating it unless it has for some reason become ambiguous (see Grice 1975; Levinson 1983: 100-165; specifically with respect to a "Neo-Gricean" account of anaphora see Levinson 1987, 1991; Huang 1999; Blackwell 2001). A related point from the standpoint of cognitive linguistics is that more minimal forms, in contexts that allow them, may be favored because they reduce processing costs for speakers (see Hawkins 2003: 38). Additionally, language in usage is designed to rely heavily on common ground for communication (Clark 1996, Enfield 2006b), and immediate discourse contexts are a common ground accessible to all speech participants. For these reasons, I predicted that speakers of EHQ when provided with obvious referents and given a task requiring them to refer to them would be likely to produce adjective-headed noun phrases at a rate higher 
than in the relatively random sample of natural speech represented by my corpus.

To test my prediction I created an exercise in which one speaker was given a photograph of several plastic toy cars of different sizes and colors arranged on a blue background. The first speaker was then asked to sit with his or her back to a second speaker and, without showing the photograph to him or her, to instruct the second speaker how to arrange the same set of toy cars so that they would match the photograph. ${ }^{29}$ I predicted that once an explicit discourse referent to 'cars' had been established, probably through one or more explicit uses of the noun carro early in the exercise, the participants would then begin to frequently (if not exclusively) refer to the toy cars through anaphoric use of color and size adjectives, rather than redundantly repeating the nominal referent over and over again.

\subsection{Adjectives and anaphora in pragmatic usage}

After running the same exercise eight times, four times with speakers of Cotopaxi Quichua and four times with speakers of Imbabura Quichua, I found my prediction to be strongly supported in all instances. For example, in the following transcript of Cotopaxi Quichua which covers 18 turns (each turn transcribed in one numbered line) the speakers explicitly use the noun carro as the head of a modifier noun phrase (AN) three times in lines 3, 5, and 9, and then begin using only adjective-headed noun phrases (A, AA) nine times in lines 9, 13, 16 and 18, until the end of the exercise. These occurrences are marked along the right-hand edge with arrows $(\leftarrow)$. Relevant items are underlined.
01 D: $\quad \underline{\text { Puka }} \underline{\text { carro }}$ derecha-man. red $\frac{\text { car }}{\text { right-ALL }}$ 'Red car to the right.'

02 JM: Derecha, uray-man sinka? right down-ALL nose 'Right (side), with the nose downwards?'

03 D: Na, kimi-ri-mu-n. NEG approach-REFL-CIS-3sG 'No, coming towards here.'

29. This exercise is loosely based on and inspired by those developed by members of the Language and Cognition Group of the Max Planck Institute for Psycholinguistics and collaborating researchers (particularly those tasks employed in Pederson et al. 1998). 
04 JM: Kay-ku-ka ka-shna. .. A ver, a ver DM.PRX-DIM-FOC DM.PRX-SEM to see to see apura-y. hurry-IMP 'This one like this ... Okay, okay, hurry.'

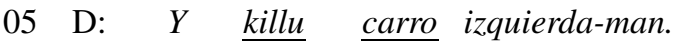
and yellow car left-ALL

'And (the) yellow car to the left.'

06 JM: Izquierda may lado-man?

left where side-ALL

'To the left on which side?'

07. D: Sinka-pura chimpa-pura riku-chi-shpa. nose-among in.front.facing-among see-CAUS-SR 'Nose to nose, in facing each other, looking at each other.'

08 JM: Ya.. ya ya. 'Okay okay okay.'

09 D: Verde uchilla shina-niti derecha-man. green little SEM-just right-ALL 'Little green just to the right.'

Chay uku-niti tiya-chi-shpa puka carro $\leftarrow$ [AN] DM.DST inside-just exist-CAUS-SR red car lado-man.

side-ALL

'Right inside there, standing next to the red car.'

10 JM: Sinka-ta uray-man chura-sha?

nose-ACC down-ALL put-FUT.1sG

'Should I put the nose downwards?'

11 D: Na chimpa-pura, chay NEG in.front.facing-among DM.DST chimpa-pura, chay lado fila uku in.front.facing-among DM.DST side row inside fila... row

'No, facing each other, facing that one, there on the inside row.'

12 JM: Ya ya ka-shna-lla-ta okay okay DM.PRX-SEM-LIM-ACC 'Okay okay, like this.'

13 D: Azul killu-pa lado-pi, chimpa-pura, $\leftarrow$ [A] [A] blue yellow-POss side-LOC front-between sinka-pura recto-pi riku-chi-y. nose-in.front.facing straight-LOC see-CAUS-IMP 
'Blue to yellow's side, facing each other, nose to nose, make them look straight'.

14 JM: Ya... chu- ima-shina-chari, na na

okay (?) what-SEM-EV.INF NEG NEG

'Okay, wait, what the ... no no.'

15 Child: $\underline{\text { Azul, }}, \underline{\text { azul }}$ pon, $\underline{\text { azul-ta } \ldots}$ aqui... $\leftarrow$ [A] [A] [A] blue blue put blue-Acc here

Blue, blue, put the blue ... here.

16 D: Cierto-pacha, ama explica-y. correct-EMPH NEG explain-IMP 'That's right, (but) don't explain (it to him).' $\underline{\text { Killu }}$ chay siki-pi, puka-ta $\quad$ [A] [A] yellow that rear.end-LOC red-ACC ima-shina-mi, uma-man tiya-chi-rka-ni, what-like-EV.AFF head-ALL be/exist-CAUS-PST-1SG chay-ta ña shina tiya-chi $\leftarrow$ [A] that-ACC already SEM be/exist-CAUS

yurak-ta.

white-ACC

'The yellow at that one's rear end, just how the red (is), I made you set it towards the head, now put that one the same, the white.'

17 JM: Kutin-ma ña shina-shka-ni. again-EV.AFF already SEM-PTCP-1SG 'Again how I did it.'

18 D: $\underline{\text { Yurak-ta }} \underline{\text { jatun }} \underline{\text { yurak-ta }} \underline{\text { jatun }} \leftarrow$ [A][AA] [AA]

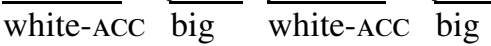
yurak-ta.

white-ACC

'White, big white, big white.'

After establishing that the discourse is about "cars" through the physical setting, through the instructions for the task and through several full AN noun phrases (puka carro 'red car'; killu carro 'yellow car') early on in the exercise, the speakers then used only anaphoric adjectival references to the cars (A: azul 'blue (car)'; killu-pa lado 'yellow (car)'s side'; yurak-ta 'white (car)'), including some multi-adjective phrases (AA: jatun yurak-ta 'big white (car)'). It should be pointed out that a particularly complex kind of anaphora is shown here, since the anaphoric scope is really the general domain of a type 'car', while at different instances specific individual cars are referred to and organized in discourse and physical space. It becomes possible to refer to a specific blue car simply by saying 'blue' within the scope of the general anaphoric do- 
main of reference of 'cars', and speakers appear to prefer the option of more minimal forms when available. In contrast to data seen in previous sections, this one short stretch of discourse in (41) features more adjectives acting as syntactic noun phrase heads (nine in total) than did my entire corpus sample (four in total, excluding adjectives with conventionalized nominal meanings), providing strong evidence that in this case the stimulus was a motivation for an increase in frequency. With speakers of Imbabura Quechua results were similar: in one session, of the total twenty-seven noun phrases featuring adjectives describing 'cars', only six had explicitly nominal heads, while the other twenty were headed by adjectives. The difference between this case of $74 \%$ total adjectives used to head noun phrases in the more controlled elicitation context versus less than $4 \%$ in the uncontrolled natural speech data from the corpus is striking evidence that one of the most relevant factors for adjectival "flexibility" in Quechua is in fact pragmatic context. ${ }^{30}$

\section{Quechua adjectives and crosslinguistic comparison}

Quechua has played a role in discussions of word class typology as a representative of a proposed crosslinguistic type of a word class system with no distinction between adjectives and nouns, yet the evidence presented here shows that using Quechua in this way is inaccurate. The implications of these conclusions are that Quechua should cease to be used as an example of such a type, and that any findings based in part on such a classification must be re-considered. Quechua should still play a part in linguistic typology, however, and in this article I hope to have offered an account with enough descriptive detail to allow for more informed crosslinguistic comparison of Quechua's word class system with those of other languages. The picture of EHQ that emerges from the data shown above is of a language with clear distinctions among the major word classes verb, noun, adjective, and adverb. There is overlap between all these classes, not just between nouns and adjectives, but there are straightforward ways of distinguishing all of them. The data show that Quechua adjectives are robustly identifiable through a range of morphosyntactic criteria, as well as through the interfaces of morphosyntax with lexical semantics and pragmatic usage contexts. These criteria are revisited and summarized here:

(i) Modification properties:

Adjectives and nouns cannot equally modify nouns. Modifying nouns form compounds $(\mathrm{NN})$ that can be further modified by adjectives (ANN).

\footnotetext{
30. Also relevant are conventionalized uses of adjectives as nouns, like uchilla, described above. However, many of these conventionalizations probably arose precisely due to their frequent usage in specific pragmatic context that eventually led to semantic changes.
} 
Modifying adjectives form attributive noun phrases (AN) that CANNOT be further modified by nouns (*NAN), but that CAN stack further adjectives (AAN). Additionally, adjectives and nouns cannot be modified equally: nouns are modified by adjectives (AN) but adjectives cannot be modified by nouns (*NA).

(ii) Morphological evidence:

Morphology commonly associated with nouns (number, case marking) can be used much more broadly beyond the noun class, making it a poor diagnosis of class membership.

(iii) Degree and intensification of adjectives:

Adjectives and adverbs can be specified for degree through reduplication or with degree words, while nouns cannot.

(iv) Word class overlaps:

Some words have lexical semantics of more than one word class. This is true for some words that have both adjectival and nominal meanings, but it is also true for all the major word classes. There is no evidence that nouns and adjectives overlap any more than any other two classes.

(v) Pragmatic constraints:

When an adjective "heads" a noun phrase speakers will seek a recoverable anaphoric referent to resolve the ambiguity; if no such referent is available, the utterance is not successful. When a noun is used as a noun phrase head no such ambiguity results.

As stated in the introduction, the criteria that yielded the above findings were chosen because they reflect common crosslinguistic patterns in word class typology, and additionally because they are appropriate tests for a language of Quechua's typological profile. Adherents to a morphosyntactic approach to word classes may not agree with the inclusion of semantic or pragmatic evidence, but in any case the morphosyntactic evidence is overwhelming on its own. The semantic and pragmatic dimensions discussed above only help to strengthen the case. Some reviewers of this article questioned why this evidence should be included if the morphosyntactic evidence is enough to prove the case. Including evidence from the interaction of morphosyntax, lexical semantics, and pragmatic usage in an account of Quechua word classes is important because disregard for these relationships has been a key element of previous misleading accounts of Quechua. Those accounts have assumed that speakers can use lexical adjectives as syntactic noun phrase heads in an unrestricted way, when a brief elicitation session with any EHQ speaker will show that this is not true. Speakers are consistently confused by adjective-headed noun phrases removed from discourse context, but not by noun-headed noun phrases. Typologists should be skeptical of comparisons that ignore ellipsis, because if any elliptical constructions can be considered fully "grammatical" outside of the contexts that they depend on, then virtually nothing can be con- 
sidered to be syntactically obligatory and much grammatical comparison becomes meaningless.

I will conclude with a final plea that in the future Quechua be evaluated by the same standards applied to other, better-known languages. The overlaps among word classes in EHQ are not any more significant than in many languages with well-established separate noun and adjective classes. If the same limited criteria that were applied by Schachter (1985) and others to Quechua were applied to well-known languages like English or Spanish, those languages could also be classified as "flexible", since they frequently modify nouns with other nouns (usually analyzed as compounds), head noun phrases with adjectives (usually analyzed as elliptical), ${ }^{31}$ apply "nominal" morphology to adjectives (in Spanish, analyzed as agreement), and show some degree of multi-class membership of roots. There are real differences among these languages' word class systems, but these can best be accounted for through detailed descriptive accounts rather than by applying pre-established types that gloss over similarities in favor of differences or vice versa. ${ }^{32}$ Such descriptions must in turn be accountable to natural speech data, since grammaticality judgments in elicitation sentences cannot tell if a form is attested in normal speech, if it is relatively frequent or rare, or if it is restricted to specific contexts. By looking at Quechua adjectives through a combination of approaches, from elicitation to a natural speech corpus analysis to controlled exercises, I hope that my account satisfies at least the basic requirements for including Quechua's word class system in future crosslinguistic comparisons, and additionally that it encourages other Quechuanists to examine their own varieties of expertise to see if they, like EHQ, have suffered from a double standard.

31. One reviewer suggested that English cannot use an adjective as an elliptical noun phrase head without the dummy pronoun (one). However, in my dialect of English (Central/South USA) this is perfectly acceptable with many adjectives in the appropriate contexts, similarly to EHQ, for example: Would you like an $M \& M$ ? Somebody ate all the greens but there are lots of reds and yellows left. It is probably true that this pattern is more pervasive in Quechua, but it can certainly be observed in English (and is also very frequent in Spanish and many other languages).

32. Following Haspelmath (2007: 125): "Instead of fitting observed phenomena into the mould of currently popular categories, the linguist's job should be to describe the phenomena in as much detail as possible, using as few presuppositions as possible. Language describers have to create language-particular structural categories for their language, rather than being able to 'take them off the shelf'. This means that they have both more freedom and more work than is often thought." 
Author's address: Max Planck Institute for Psycholinguistics, PO Box 310, 6500 AH Nijmegen, The Netherlands; e-mail: Simeon.Floyd@mpi.nl

Acknowledgements: Many thanks are owed to members of the communities of Quilapungo, Peguche, Oyacachi, and Charcay for their help with this research, especially to Delfina Cholopatín, Juan Manuel Cuchiparte, Luzmila Castañeda, and Antonio Lema for participation in elicitation exercises. Funding for the research was provided in different periods by the Fulbright Program, the National Science Foundation, and the University of Texas, and this support is greatly appreciated. I am grateful for the the helpful comments on earlier drafts provided by Pattie Epps, Nora England, Martine Bruil, Felix Julca, Thomas Hörberg, Robert Van Valin, Jr., and three anonymous reviewers. Any errors are my own.

Abbreviations: 1/2/3 1st/2nd/3rd person; ABL ablative; ACC accusative; ALL allative; ART article; AUG augmentative; CAUS causative; CIS cislocative; COM comitative/instrumental; DIM diminutive; DM.DST distal demonstrative; DM.PRX proximate demonstrative; DR different reference; EMPH emphatic; EV.AFF affirmative evidential; EV.INF inferential evidential; FOC focus; FUT future; IMP imperative; INF infinitive; LIM limitative; LOC locative; NEG negator; NMLZ nominalizer; PL plural; POSS possessive; PROG progressive; PST past; PTCP participle; RECP reciprocal; REFL reflexive; SEM semblative; SG singular; sP Spanish phrase (not for single borrowings); SR same reference.

\section{References}

Ansaldo, Umberto, Jan Don \& Roland Pfau (eds.). 2008. Parts of speech: Descriptive tools, theoretical constructs. Studies in Language 32. 505-785.

Baker, Mark. C. 2003. Lexical categories: Verbs, nouns, and adjectives. Cambridge: Cambridge University Press.

Baker, Mark C. 2010. On the syntax and pragmatics of lexical categories: A comment on Mark Smith. Linguistics 48. 779-785.

Beér, Robert \& Delina Beér. 2006. Vocabulario comparativo: Quechua Cuzco-Collao - quechua boliviano. Unpublished manuscript, Brighton. http://homepage.ntlworld.com/robert_beer/ Vocabulario\%20comparativo\%20Quechua\%20cuzqueno\%20Quechua\%20boliviano\% 20 $\% 2022 \% 20$ Apr\%2006.PDF

Beér, Robert, Armando Muyolema \& Hernán S. Aguilar. 2006. Vocabulario comparativo: Quechua ecuatoriano - quechua ancashino. Unpublished manuscript, Brighton. http:// homepage.ntlworld.com/robert_beer/Vocabulario\%20comparativo\%20Quechua\%20ecuator \%20Quechua\%20ancash\%20-\%2020\%200ct\%2006.PDF

Beck, David. 2002. The typology of parts of speech systems: The markedness of adjectives. New York: Routledge.

Berg, Thomas. 2000. The position of adjectives on the noun-verb continuum. English Language and Linguistics 4. 269-293.

Blackwell, Sarah E. 2001. Testing the neo-Gricean pragmatic theory of anaphora: The influence of consistency constraints on interpretations of coreference in Spanish. Journal of Pragmatics 33. 901-994.

Blake, Barry J. 2001. Case. 2nd edn. Cambridge: Cambridge University Press.

Catta Q., Javier 1994. Gramática del quichua ecuatoriano. 3rd edn. Quito: Abya Yele.

Chafe, Wallace. 2004. Do all languages have adjectives? Paper presented at the annual meeting of the Society for the Study of the Indigenous Languages of the Americas (SSILA), January 8-11, 2004, Boston.

Clark, Herbert H. 1996. Using language. Cambridge: Cambridge University Press.

Cole, Peter. 1982. Imbabura Quechua (Lingua Descriptive Studies 5). Amsterdam: North Holland.

Cordero, Luís. 1892 [1992]. Diccionario quichua-castellano castellano-quichua. Quito: Imprenta del Gobierno. Reprint, Quito: Corporación Editora Nacional, 1992.

Croft, William. 2001. Radical Construction Grammar: Syntactic theory in typological perspective. Oxford: Oxford University Press. 
Croft, William. 2005.Word classes, parts of speech and syntactic argumentation. Linguistic Typology $9.431-441$.

Croft, William. 2010. Pragmatic functions, semantic classes and lexical categories. Linguistics 48. $787-796$.

Dixon, R. M. W. 2004. Adjective classes in typological perspective. In R. M. W. Dixon \& Alexandra Aikhenvald (eds.), Adjective classes: A crosslinguistic typology, 1-49. Oxford: Oxford University Press.

Dixon, R. M. W. 2010. Basic linguistic theory, Vol. 2: Grammatical topics. Oxford: Oxford University Press.

Dryer, Matthew S. 2006. Descriptive theories, explanatory theories, and basic linguistic theory. In Felix Ameka, Alan Dench \& Nicholas Evans (eds.), Catching language: Issues in grammar writing, 207-234. Berlin: Mouton de Gruyter.

Enfield, Nicholas. J. 2006a. Heterosemy and the grammar-lexicon trade-off. In Felix K. Ameka, Alan Dench \& Nicholas Evans (eds.), Catching language: The standing challenge of grammar writing, 297-320. Berlin: Mouton de Gruyter.

Enfield, Nicholas J. 2006b. Social consequences of common ground. In Nick J. Enfield \& Stephen C. Levinson (eds.), Roots of human sociality: Culture, cognition and interaction, 399-430. Oxford: Berg.

Evans, Nicholas. 2006. Dyadic constructions. In Keith Brown (ed.), Encyclopaedia of Language and Linguistics (2nd edn.), 24-28. Oxford: Elsevier.

Evans, Nicholas \& Toshiki Osada. 2005. Mundari: The myth of a language without word classes. Linguistic Typology 9. 351-390.

Gómez Rendón, Jorge. 2008. Typological and social constraints on language contact: Amerindian languages in contact with Spanish (LOT Dissertation Series 188). Utrecht: LOT.

Grice, H. Paul. 1975. Logic and conversation. In Peter Cole \& Jerry L. Morgan (eds.), Speech acts (Syntax and Semantics 3), 41-58. New York: Academic Press.

Guerrero, Lilián \& Robert Van Valin Jr. 2004. Yaqui and the analysis of primary object languages. International Journal of American Linguistics 70. 290-319.

Hastings, Rachel. 2003. The semantics of discontinuous noun phrases in Quechua. In Jan Anderssen, Paula Menéndez-Benito \& Adam Werle (eds.), SULA2: The proccedings of the Second Conference on the Semantics of Under-Represented Languages in the Americas, 35-55. Amherst, MA: Graduate Linguistics Students' Association, University of Massachusetts at Amherst. http://www.umass.edu/linguist/events/SULA/SULA_2003_cd/files/hastings.pdf

Haspelmath, Martin. 2007. Pre-established categories don't exist: Consequences for language description and typology. Linguistic Typology 11. 119-132.

Hawkins, John A. 2003. Efficiency and complexity in grammars. Oxford: Oxford University Press.

Hengeveld, Kees. 2007. Parts-of-speech systems and morphological types. ACLC Working Papers 2(1). 31-48. http://www.hum.uva.nl/aclc-papers/working_papers.cfm

Hengeveld, Kees \& Jan N. M. Rijkhoff. 2005. Mundari as a flexible language. Linguistic Typology 9. 406-431.

Hengeveld, Kees \& Marieke Valstar. 2010. Parts-of-speech systems and lexical subclasses. Linguistics in Amsterdam 3(1). http://www.linguisticsinamsterdam.nl

Hengeveld, Kees \& Eva van Lier. 2008. Parts of speech and dependent clauses in Functional Discourse Grammar. Studies in Language 32. 753-785.

Huang, Yan. 1999. Discourse anaphora: Four theoretical models. Journal of Pragmatics 32. 151176.

Huerta, Alonso de. 1616 [1993]. Arte de la lengua quechua general de los yndios de este reyno del Piru. Los Reyes: Francisco del Canto. Reprinted as Arte breve de la lengua quechua. Quito: Corporación Editora Nacional, 1993.

Levinson, Stephen C. 1983. Pragmatics. Cambridge: Cambridge University Press.

Levinson, Stephen C. 1987. Pragmatics and the grammar of anaphora: A partial pragmatic reduction of Binding and Control phenomena. Journal of Linguistics 23. 379-434. 
Levinson, Stephen C. 1991. Pragmatic reduction of the Binding Conditions revisited. Journal of Linguistics 27. 107-161.

Munro, Pamela. 2005. From parts of speech to the grammar. Studies in Language 30. 307-349

Muysken, Pieter \& Claire Lefebvre. 1988. Mixed categories: Nominalizations in Quechua. Dordrecht: Kluwer.

Nikolaeva, Irina. 2008. Between nouns and adjectives: A constructional view. Lingua 118. 969996.

Olawsky, Knut. 2004. What is a noun? What is an adjective? Problems of classification in Dagbani. Journal of African Languages and Linguistics 25. 127-148.

Palancar, Enrique L. 2006. Property concepts in Otomí: A language with no adjectives. International Journal of American Linguistics 72. 325-366.

Paris, Julio. 1961. Gramática de la lengua quichua actualmente en uso entre los indígenas del Ecuador. 3rd edn. Quito: Editorial Santo Domingo.

Pederson, Eric, Eve Danziger, David G. Wilkins, Stephen C. Levinson, Sotaro Kita \& Gunter Senft. 1998. Semantic typology and spatial conceptualization. Language 74. 557-589.

Peterson, John. 2005. There's a grain of truth in every "myth", or, Why the discussion of lexical classes in Mundari isn't quite over yet. Linguistic Typology 9. 391-405.

Post, Mark. 2008. Adjectives in Thai: Implications for a functionalist typology of word classes. Linguistic Typology 12. 339-391.

Santo Tomás, Fray Domingo. 1560 [1995]. Grammatica o arte de la lengua general de los indios de los reynos del Perú. Valladolid: Francisco Fernandez de Cordoua. Reprint, Cuzco: Centro de Estudios Regionales Andinos "Bartolomé de las Casas", 1995.

Schachter, Paul. 1985. Parts-of-speech systems. In Timothy Shopen (ed.), Language typology and syntactic description, Vol.1: Clause structure, 3-61. Cambridge: Cambridge University Press.

Schachter, Paul \& Timothy Shopen. 2007. Parts-of-speech systems. In Timothy Shopen (ed.), Language typology and syntactic description (2nd edn.), Vol.1: Clause structure, 1-60. Cambridge: Cambridge University Press.

Smit, Niels. 2007. Dynamic perspectives on lexical categorisation. ACLC Working Papers 2(1). 49-75. http://www.hum.uva.nl/aclc-papers/working_papers.cfm

Smith, Mark. 2010. Pragmatic functions and lexical categories. Linguistics 48. 717-777.

Warren, Beatrice. 1987. Semantic patterns of noun-noun compounds (Gothenburg Studies in English 41). Göteborg: Acta Universitatis Gothoburgensis.

Weber, David John. 1989. A grammar of Huallaga (Huanuco) Quechua. Berkeley, CA: University of California Press. 